\title{
High Performance Platinum Group Metal-Free Cathode Catalysts for Microbial Fuel Cell (MFC)
}

\author{
Mounika Kodali, Rohan Gokhale, Carlo Santoro, ${ }^{*}$ Alexey Serov, ${ }^{*}$ Kateryna Artyushkova, ${ }^{*}$ \\ and Plamen Atanassov ${ }^{*, z}$
}

Center Micro-Engineered Materials (CMEM), Department of Chemical and Biological Engineering,

University of New Mexico, Albuquerque, New Mexico 87131, USA

\begin{abstract}
The oxygen reduction reaction (ORR) at the cathode is usually the limiting step in microbial fuel cells and improvements have to be done to increase the performances and reduce the cost. For the first time, iron-based catalysts were synthesized utilizing the polymerization-pyrolysis method and tested successfully in neutral media and in working microbial fuel cells (MFCs). The catalysts were synthesized using polymerization, salt formation, mixed with iron salt and pyrolyzed at $850^{\circ} \mathrm{C}(\mathrm{PABA}-850)$ and $950^{\circ} \mathrm{C}(\mathrm{PABA}-$ 950) respectively. To study the kinetics, electro-activity of the catalysts was investigated using rotating ring disk electrode (RRDE). Results showed that PABA-850 had higher catalytic activity compared to that of PABA-950. Both Fe-catalysts had much better activity compared to activated carbon (AC) used as a baseline. Catalysts were then integrated into air breathing cathodes (loading $1 \mathrm{mg} \mathrm{cm}^{-2}$ ) and tested in single chamber MFC. The power peak obtained was $178 \pm 3 \mu \mathrm{Wcm}^{-2}$ for PABA-850. Comparable power was produced from PABA-950 $\left(173 \pm 3 \mu \mathrm{Wcm}^{-2}\right)$. AC power output was $131 \pm 4 \mu \mathrm{Wcm}^{-2}$ that was roughly $40 \%$ lower compared to Fe-based catalysts. Those results demonstrated that the addition of platinum group metal free (PGM-free) catalysts increased the output of the MFCs substantially. Fe-based catalysts seem to be suitable for large-scale MFC applications.

(c) The Author(s) 2016. Published by ECS. This is an open access article distributed under the terms of the Creative Commons Attribution 4.0 License (CC BY, http://creativecommons.org/licenses/by/4.0/), which permits unrestricted reuse of the work in any medium, provided the original work is properly cited. [DOI: 10.1149/2.0061703jes] All rights reserved.

(c) BY
\end{abstract}

Manuscript submitted September 20, 2016; revised manuscript received October 26, 2016. Published December 7, 2016. This paper is part of the JES Focus Issue on Biological Fuel Cells.

Biological Fuel Cell is an interesting technology that utilizes both electrochemical and microbiological/enzymatic aspects for degrading organics and simultaneously producing electricity or transforming organics or gaseous products into viable compounds/substances. ${ }^{1,2}$ One of the most studied biological fuel cell till now is the Microbial Fuel Cells (MFCs) due to their potential of substituting the existing cost-extensive wastewater treatment plants. In fact, in an MFC, electroactive bacteria on the anode electrode oxidize organics generating electricity. The red-ox process is then terminated with the reduction of an oxidant at the cathode. Oxygen is the most used oxidant mainly due to its high reduction potential and its large availability in gaseous form. Several limitations hinder the commercialization of MFCs in large scale. ${ }^{3,4}$ The problems are related to the high materials costs, the poor red-ox electrochemical performances and the relatively low durability of the electrodes. For the large part of the scientific community, the main problem is related to the oxygen reduction reaction (ORR) at the cathode. ${ }^{5,6}$ This reaction is severely limited by high overpotentials $^{5,6}$ and not optimized working conditions. ${ }^{5,6}$ The theoretical value for ORR at $\mathrm{pH} 7.5$ is $0.606 \mathrm{~V}$ (vs $\mathrm{Ag} / \mathrm{AgCl}$ ). Except for selective enzymes (laccase and bilirubine oxidase) performing ORR, in which the overpotentials are limited to $50-100 \mathrm{mV},{ }^{7-9}$ higher overpotentials are measured using abiotic and inorganic catalysts. ${ }^{5,6}$ Unfortunately, enzymes are not stable in polluted environments as previously demonstrated. ${ }^{10}$

By far, Pt has been the most utilized catalysts for ORR in MFCs. ${ }^{11,12}$ Despite Pt is high electrocatalytic activity toward ORR in acidic media, ${ }^{13}$ its performance lowers down significantly in neutral and alkaline media. ${ }^{14}$ This is mainly due to the fact that anions bind strongly to Pt decreasing its activity substantially. ${ }^{15,16}$ Consequently, both high cost (with low power production) and problematic deactivation due to the natural presence of anions promoted the efforts in different alternative directions.

The most investigated path in the past few years is the utilization of carbonaceous catalysts in which, undoubtedly, high surface area and high conductivity present main successful characteristics. ${ }^{17,18}$ Particularly, activated carbon was used as cathode catalysts for MFCs. ${ }^{19-24}$

*Electrochemical Society Member.

${ }^{\mathrm{z} E}$-mail: plamen@unm.edu
Since 2009, in which AC was first proposed, ${ }^{24}$ several advancements have been achieved in AC-based cathode catalysts for MFCs. In fact, it has been shown that i) surface chemistry, ${ }^{22}$ ii) temperature treatment, ${ }^{19,25}$ iii) pressure applied, ${ }^{19}$ iv) AC loading, ${ }^{22}$ v) content of binder (e.g. PTFE), ${ }^{22}$ vi) addition of carbon black, ${ }^{26}$ affect the cathode performances and the MFC output significantly. AC seems to be the cheapest and efficient solution to adopt for scaling up MFCs. Longterm performance of MFCs using AC cathode showed very slight degradation over 16 months of operation, indicating that the material is very robust and reliable. ${ }^{27}$ However, the overpotentials of AC are high and the kinetics of ORR is poor.

Lately, PGM-free catalysts have been used to enhance ORR in neutral working conditions. ${ }^{11,12,18}$ PGM-free catalysts showed slightly worse performance compared to Pt in acidic media, similar or higher compare to $\mathrm{Pt}$ in neutral media and superior compared to Pt in alkaline media. ${ }^{14}$ PGM-free catalysts are mainly based on a carbon/nitrogen matrix with atomically dispersed particles of a transitional metal. ${ }^{28-30}$ $\mathrm{Fe}, \mathrm{Co}, \mathrm{Ni}, \mathrm{Mn}$ and $\mathrm{Cu}$ (earth abundant metals) are the most used and studied metals in PGM-free cathode catalysts in MFC. ${ }^{11,12}$ Those catalysts have the advantage of being made from earth abundant metals and, consequently, the cost of production is relatively low and not a subject to geo-political issues. The utilization of PGM-free catalysts for ORR in MFCs has been raised exponentially in the past few years. ${ }^{11}$ It has been shown that the addition of PGM-free catalysts into the cathode positively affects the power output compared to the utilization of plain $\mathrm{AC} .^{27,31}$ In fact, several studies have integrated PGM-free catalysts into the cathodes with fruitful benefits. Here we mention some of the successful and relevant investigation concerning iron, ${ }^{31-35}$ manganese, ${ }^{36,37}$ cobalt, $^{38-40}$ nickel $^{41,42}$ and copper. ${ }^{43}$ Few literature reviews on PGM-free catalysts utilization have also been recently presented. ${ }^{11,12,18}$

In the past years, our group has developed several PGM-free catalysts that have been successfully incorporated in the cathode for $\mathrm{MFC}^{14,44,45}$ and in electrodes for supercapacitive MFC (SCMFC). ${ }^{46,47}$ The catalysts were all prepared using sacrificial support method (SSM) technique in which highly porous open frame structure was formed. ${ }^{4-50}$ Particularly, iron-aminoantipyrine (Fe-AAPyr) has been successfully used in double chamber MFC (DCMFC), ${ }^{14}$ ceramic based MFC $^{44}$ and single chamber MFC. ${ }^{45}$ Further advancements have been shown with the investigation of iron-based catalysts 
pyrolized with other low cost precursors named Niclosamide, Ricobendazole, Guanosine, Succinylsulfathiazole, Sulfacetamide, Quinine, Sulfadiazine and Pyrazinamide ${ }^{51}$ and among them, Ricobendazole and Niclosamide have been tested over 32 days showing stable performances. ${ }^{52}$

In this present work, catalyst formulation and preparation was changed from previously reported studies, and no SSM was applied. In the current report, pyrolysis of polymer salt with iron salt ${ }^{53}$ was performed for the first time to synthesize novel catalysts utilized in neutral media and applied in MFC studies. Catalysts kinetics was studied utilizing rotating ring disk electrode technique (RRDE). The catalysts were then incorporated into air-breathing cathodes and tested in phosphate buffer. Cathodes were then assembled in working MFCs, and polarization curves were carried out.

\section{Materials and Methods}

Synthesis process used for catalysts preparation.-4-amino benzoic acid (5 g, $36.4 \mathrm{mM}$ ) was dissolved in $300 \mathrm{~mL}$ deionized water. An equimolar amount of radical generator, Ammonium persulfate $(8.3 \mathrm{~g})$ was added under stirring for the polymerization of the reactant to take place. The reaction proceeded for $48 \mathrm{~h}$. The reaction mixture turned dark in color, and the polymerized product was separated by centrifugation. An equimolar amount of $\mathrm{NaOH}$ pellets was added $(1.5 \mathrm{~g})$ in the product dispersed in water, and the polymer became soluble due to the formation of the corresponding salt. The water was then dried off in an oven to obtain the polymer salt product ${ }^{53}$ A calculated amount of iron (III) nitrate was added to the polymer salt, and the mixture was ground in a mortar, homogenously. The mixture was then pyrolyzed at $950^{\circ} \mathrm{C}$ for $1 \mathrm{~h}$ in $\mathrm{N}_{2}\left(7 \% \mathrm{H}_{2}\right)$. The pyrolyzed material obtained was ground in a mortar and added to a large amount of dilute nitric acid (under stirring for $12 \mathrm{~h}$ ) to remove by-products (metal salts) and obtain pure carbon catalyst. The carbon catalyst was isolated by centrifugation and subjected to a second heat-treatment $\left(950^{\circ} \mathrm{C}, 1 \mathrm{~h}\right)$ in ammonia gas. A similar process was used again to generate a variation of the first catalyst. In this case, the only difference was the first pyrolysis temperature, $850^{\circ} \mathrm{C}$.

Catalysts surface chemistry and morphology.-The catalyst surface morphology was studied using Scanning Electron Microscopy (SEM) Hitach S-800 instrument. Images were acquired at different resolutions. Kratos Axis Ultra DLD spectrometer was used to obtain high resolution X-ray Photoelectron Spectra (XPS) from materials. 3 points per sample were analyzed. Wide scan and high resolution $\mathrm{O}$ $1 \mathrm{~s}, \mathrm{~N} 1 \mathrm{~s}, \mathrm{C} 1 \mathrm{~s}$ and Fe $2 \mathrm{p}$ spectra were acquired without charge neutralization at $225 \mathrm{~W} \mathrm{Al} \mathrm{K} \alpha$ monochromatic X-ray source. The spectra were processed in CASAXps.

Cathode preparation.-The cathode was prepared as previously presented. ${ }^{52}$ Activated carbon (AC, Norit SX plus), carbon black (CB, $50 \%$ acetylene, Alfa Aesar) and polytetrafluoroethylene (PTFE, 60\% emulsion, Sigma Aldrich) were mixed in a blender for at least 5 minutes. The ratio of the three ingredients was $70 \%, 10 \%$, and $20 \%$ respectively. Since AC is not that conductive due to its intrinsic high surface area, CB was added to increase the cathode conductivity. The mixture was then weighted and added to a metallic pellet die with a circular shape. The mixture was pressed at $5 \mathrm{mT}$ for 5 minutes on a stainless steel mesh (SS, MacMaster) till a uniform pellet was formed in the top of the mesh. Three different cathodes have been investigated each one in triplicate: the first having just activated carbon (AC) as a catalyst, the second one was based on $\mathrm{AC}$ and PABA $\left(850^{\circ} \mathrm{C}\right)$ and the last one was based on $\mathrm{AC}$ and PABA $\left(950^{\circ} \mathrm{C}\right)$. In all of them, the $\mathrm{AC} / \mathrm{CB} / \mathrm{PTFE}$ mixture had a loading of $40 \mathrm{mg} \mathrm{cm}^{-2}$. In the case of addition of Fe-PABA-850 or Fe-PABA-950, a catalyst loading of 1 $\mathrm{mg} \mathrm{cm}-2$ was added in the mixture before the pressure was applied.

Microbial fuel cell assembly and operating conditions.-After the RRDE tests done in neutral media, the cathode was inserted in a working MFC. MFC was a glass bottle with an empty volume of
$125 \mathrm{~mL}$ modified with a lateral hole in which the cathode was accommodated and screwed. No membrane was used to separate anode and cathode, with the first completely immerged in the solution and the second having a face exposed to the solution and one open to air. The bottle was filled with a mixture of $50 \%$ in volume of $0.1 \mathrm{M}$ potassium phosphate $(\mathrm{K}-\mathrm{PB})$ and $0.1 \mathrm{M}$ potassium chloride $(\mathrm{KCl})$ and $50 \%$ in volume of activated sludge taken from the Albuquerque Southeast Water Reclamation Facility (New Mexico, USA). Sodium acetate in a concentration of $3 \mathrm{gL}^{-1}$ was added in the solution as a food source for electroactive bacteria. The solution conductivity of the electrolyte was $16 \mathrm{mScm}^{-1}$. The anodes were two carbon brushes (Millirose, USA) based on carbon fibers twisted on a titanium core and each brush had a diameter of $3 \mathrm{~cm}$ and height of $3 \mathrm{~cm}$. The anodes were well operating from previously experiments and already colonized with electroactive bacteria. ${ }^{52}$ The MFCs tests were done at room temperature quantified in $22 \pm 1^{\circ} \mathrm{C}$.

Electrochemical measurements (RRDE, MFCS tests).-_Rotating Ring Disk Electrode (RRDE) measurements were performed for obtaining the oxygen reduction current at the glassy carbon disk and the peroxide oxidation current at the platinum ring. The electrolyte used was $0.1 \mathrm{M} \mathrm{K}-\mathrm{PB}$ with $0.1 \mathrm{M} \mathrm{KCl}$. The electrolyte was saturated with pure $\mathrm{O}_{2}$ saturated. The rotation speed was kept at $1600 \mathrm{rpm}$ during the measurements, and the scan rate was $5 \mathrm{mVs}^{-1}$. The catalyst ink was prepared by adding $2.5 \mathrm{mg}$ of the catalyst to $850 \mu \mathrm{L}$ IPA:DI (2:1) and $150 \mu \mathrm{L} 0.5 \mathrm{wt} \%$ Nafion. The ink was drop-casted after sonication on to the RRDE disk at a loading of $100 \mu \mathrm{g} \mathrm{cm}^{-2}$.

Once the cathode was prepared, it was screwed on a working MFC. The MFC was left in open circuit voltage (OCV) for at least three hours. Three electrode configuration was used to characterize the electrochemical performances on the MFC. Particularly, one channel of the potentiostat was used to measure the overall polarization curve in which the anode was used as the working electrode and the cathode as the counter electrode short-circuited with the reference channel. An additional potentiostat channel was used to measure separately anode and cathode potentials during the polarization curve. In this case, the anode was used as the working electrode and the cathode as the counter electrode and $\mathrm{Ag} / \mathrm{AgCl} 3 \mathrm{M} \mathrm{KCl}(+210 \mathrm{mV}$ vs $\mathrm{SHE})$ as reference electrode inserted into the cell. Polarization curves were done between $\mathrm{OCV}$ and $0 \mathrm{mV}$ at a scan rate of $0.2 \mathrm{mVs}^{-1}$. Anode and cathode polarization curves were detected simultaneously and represented separately. Power curves were constructed from the overall polarizations curves multiplying the voltage for the current obtained $(\mathrm{P}=\mathrm{V} \times \mathrm{I})$. The power and the current were represented in function of the geometric cathode area exposed to the liquid solution $\left(2.85 \mathrm{~cm}^{-2}\right)$.

\section{Results and Discussion}

Surface chemistry and morphology.-Surface composition of both materials was studied by XPS. The sample obtained at a higher temperature of pyrolysis has slightly more $\mathrm{N}-1.2 \%$ vs $0.9 \%$ and at the same time less $\mathrm{Fe}-0.07$ at $\%$ vs $0.12 \%$ for $850^{\circ} \mathrm{C}$ sample. The nitrogen chemistry is also quite different depending on the temperature of pyrolysis as shown in Figure 1. Sample pyrolyzed at lower temperature has pyrrolic nitrogen as a major nitrogen type at $34.5 \%$ relative with pyridinic at $23.1 \%$ and $\mathrm{N}$ coordinated to iron at $24.7 \%$. Pyrrolic nitrogen decreased to $24.7 \%$ for a sample at a higher temperature of pyrolysis, while both pyridinic and Nx-Fe centers are present in higher amounts, 31.0 and $31.6 \%$ respectively. The ratio of the amount of $\mathrm{Nx}-\mathrm{Fe}$ to atomic $\%$ of $\mathrm{Fe}$ is only $\sim 2$ pointing that there is an excess of $\mathrm{Fe}$ that is not atomically coordinated to nitrogen. For sample pyrolyzed at $950^{\circ} \mathrm{C}$, the same ratio is $\sim 5$ which means that all the iron that present is coordinated to nitrogen as $\mathrm{Fe}-\mathrm{Nx}$ centers.

Scanning electron microscopy (SEM) images (Figures 2a-2d) of the catalyst display the unique morphology of the material. The catalyst possesses a porous morphology with graphitic flakes containing a large number of holes. The flaky assembly can be seen in Figure $2 \mathrm{a}$ and $2 \mathrm{~b}$ in addition to a large number of holes clearly observed 
a)

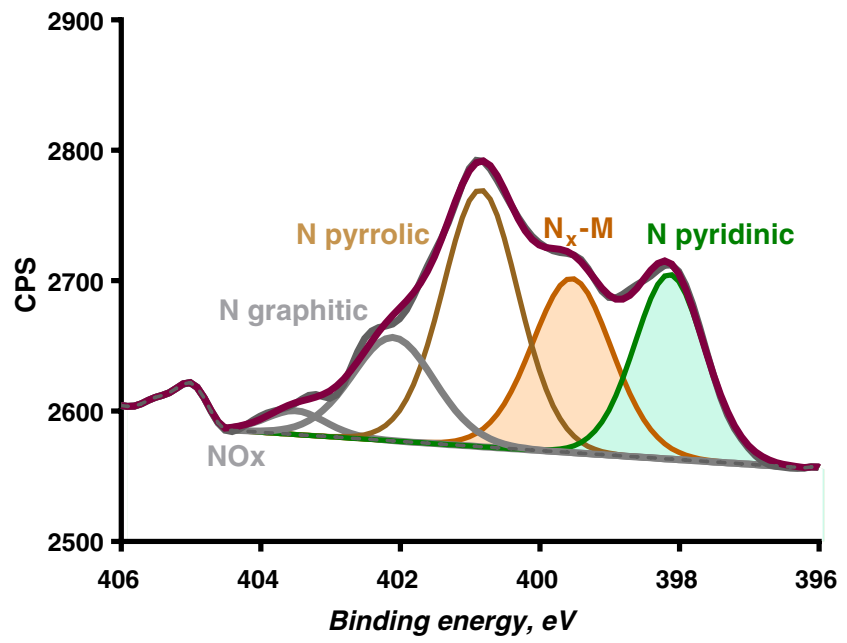

b)

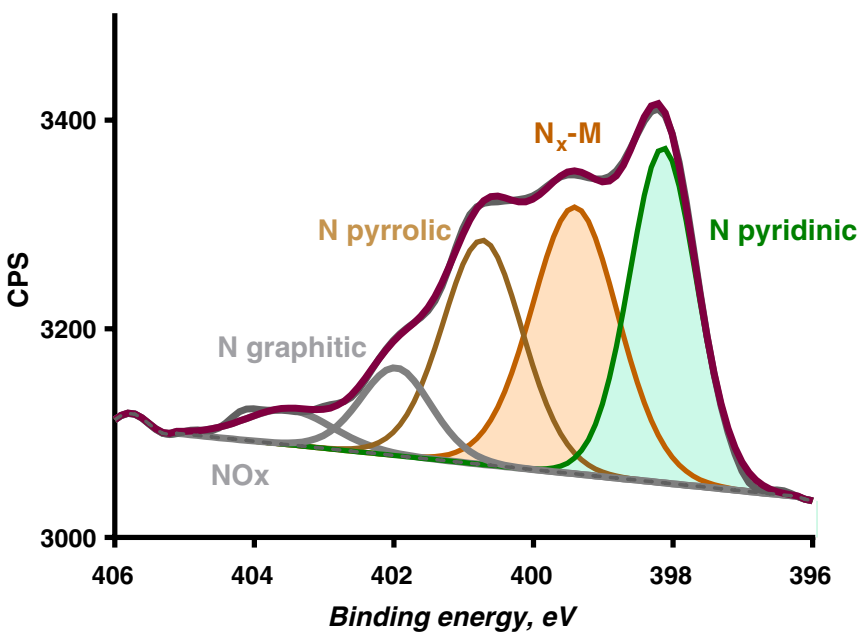

Figure 1. High resolution $\mathrm{N}$ 1s spectrum from a) PABA-850 and b) PABA-950 samples.

in Figure 2c and 2d. This 'Swiss cheese' like morphology is not observed very frequently in graphitic carbon catalysts. This peculiar structure, containing a network of large pores throughout the material, can provide high surface area and easy access of the electrolyte for electro-catalytic reactions, making it an efficient catalytic system.

$\boldsymbol{R} \boldsymbol{R D E}$ analysis. - The oxygen reduction current (disk) for the FePABA catalysts is shown in Figure 3a. The reduction onset potential for both the cases (PABA 950 and 850) is similar having an approximate value of $+0.2 \mathrm{~V}$ ( $\mathrm{vs} \mathrm{Ag} / \mathrm{AgCl}$ ). The half wave potential, which is an important aspect for a potential catalyst is observed to be more positive for the PABA-950 case $(\sim 0.1 \mathrm{~V})$. However, the limiting current density is less as compared to the PABA-850 case. In the PABA-850 case, the half wave potential is $\sim 0.065 \mathrm{~V}$ along with a limiting current density of $\sim-3 \mathrm{~mA} \mathrm{~cm}^{-2}$. From the disk current, it is quite clear that both Fe-PABA catalysts display a reasonable performance of oxygen reduction in the neutral medium. Both the catalysts exhibit a very low peroxide yield (Figure 3b). $\% \mathrm{H}_{2} \mathrm{O}_{2}$ is calculated using Eq. 1 . Hydrogen peroxide is a catalytic poison and is generated by the 2electron mechanism. Any good ORR catalyst should have a minimum peroxide production during the process. PABA- 850 is seen to have a varying peroxide production with different ranges, $4-7 \%$ in the range
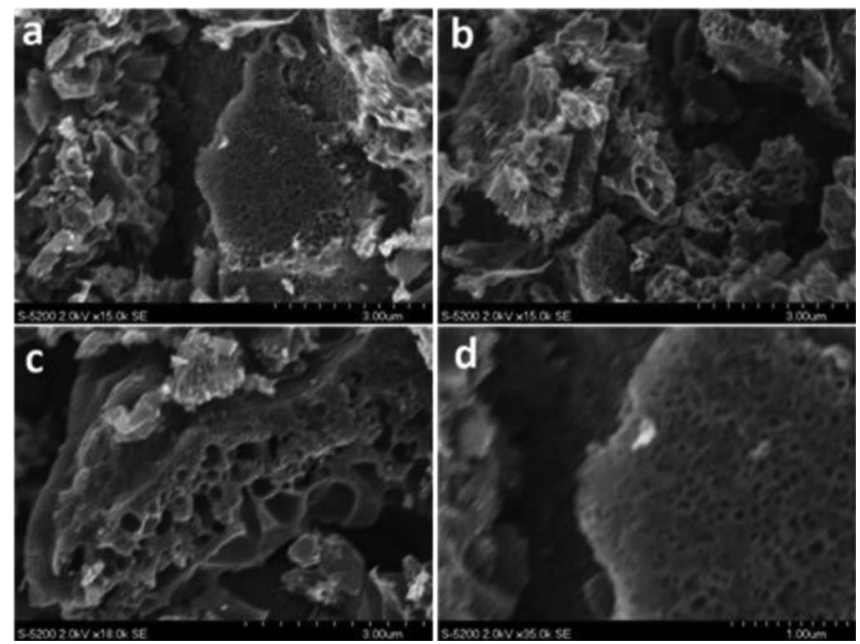

Figure 2. (a-d) Scanning electron microscopy images of catalyst at different resolutions. of potentials $-0.2 \mathrm{~V}$ to $-0.5 \mathrm{~V}$. The peroxide production further increases toward more negative potentials. The PABA-950 case shows a slightly lower peroxide production, $2-4 \%$ in the range of $-0.2 \mathrm{~V}$ to $-0.5 \mathrm{~V}$ and also shows a gradual increase at more negative potentials. In the entire range, PABA-950 generates less peroxide as compared to PABA-850.

$$
\% \mathrm{H}_{2} \mathrm{O}_{2}=100 \times \frac{2 I_{R} / N}{I_{D}+I_{R} / N}
$$

Depending on the nature of the catalysts, ORR can occur by two different mechanisms, 4-electron and 2-electron mechanisms. 4-electron mechanism is usually the more efficient pathway which generates less peroxide rather than the 2-electron case. The number of electrons transferred in the mechanism of reduction for the Fe-PABA catalysts is shown in Figure 3b. It is clearly observed that in both cases PABA-850 and PABA-950, the pathways approach a direct 4-electron route. The number of electrons is calculated following Eq. 2 :

$$
\mathrm{n}=\frac{4 I_{\text {disc }}}{I_{\text {disc }}+\frac{I_{\text {ring }}}{N}}
$$

Polarization curves and power curves.-Overall polarization curves were run after the MFCs were in stable conditions with steady OCV. Starting point was measured similar for Fe-PABA-850 and FePABA-950 and it was $700 \pm 12 \mathrm{mV}$ (Figure 4a). Lower OCV (623 \pm $3 \mathrm{mV}$ ) was measured for AC cathode MFC (Figure 4a). Polarization curves followed a quasi-linear trend indicating that under the investigated conditions the ohmic resistance is the main limitation (Figure 4a). Similar short circuit current was achieved by Fe-PABA- 850 and Fe-PABA-950 $\left(1280 \pm 50 \mu \mathrm{Acm}^{-2}\right)$. $20 \%$ lower short-circuit current was achieved by AC-cathode $\left(1091 \pm 38 \mu \mathrm{Acm}^{-2}\right)$. From the polarization curves, power curves were calculated (Figure 4b). Febased catalysts had power curves higher than AC-cathodes indicating that the utilization of PGM-free certainly has a positive effect on the performances of an MFC. The highest power density during this investigation was achieved by Fe-PABA-850 with $178 \pm 3 \mu \mathrm{Wcm}^{-2}$. Slightly lower power density $\left(173 \pm 3 \mu \mathrm{Wcm}^{-2}\right)$ was achieved by Fe-PABA-950. Much lower power density $\left(131 \pm 4 \mu \mathrm{Wcm}^{-2}\right)$ was measured when AC-cathode was used as the cathode catalyst. Separate anode and cathode polarization curves were also collected during the polarization curves. The single electrode profiles are presented in Figure $4 \mathrm{c}$. It must be noted that anode profile trends can be overlapped with no substantial difference. In parallel, the cathode profile is quite different. Higher open circuit potential (OCP) was measured with 

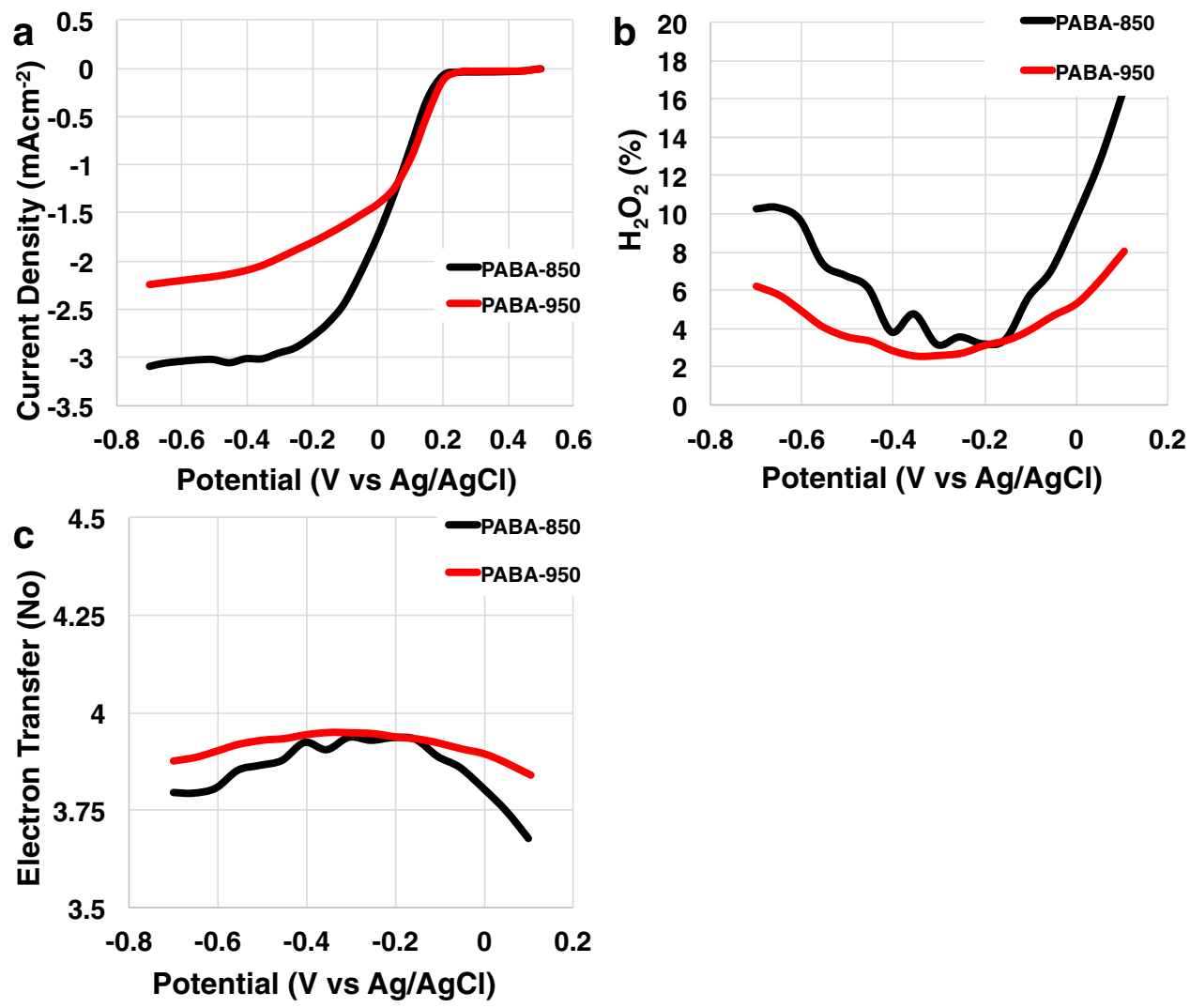

Figure 3. RDE current (a), $\mathrm{H}_{2} \mathrm{O}_{2} \%$ production (b) and electron transfer (c) of PABA- 850 and PABA- 950 .

Fe-based catalysts indicating a distinguishable advantage of PGMfree catalysts. In fact, Fe-based catalysts had higher OCP identified in $183 \pm 6 \mathrm{mV}$ (vs $\mathrm{Ag} / \mathrm{AgCl}$ ) that was roughly $60 \mathrm{mV}$ higher than AC-catalyst (Figure 4c). Fe-based catalysts also showed more electrocatalytic activity compared to AC through the cathode polarization
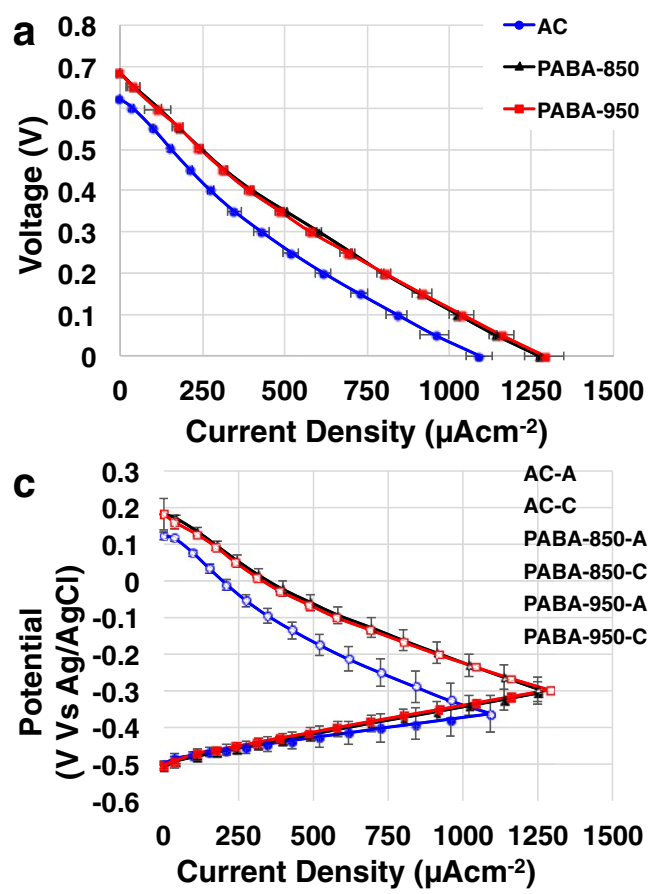

curves (Figure 4c). The difference in the overall polarization curve was driven by the cathode performance.

Outlook and comparison with existing literature.-Cathode behavior in neutral media has been identified as the main issue to be

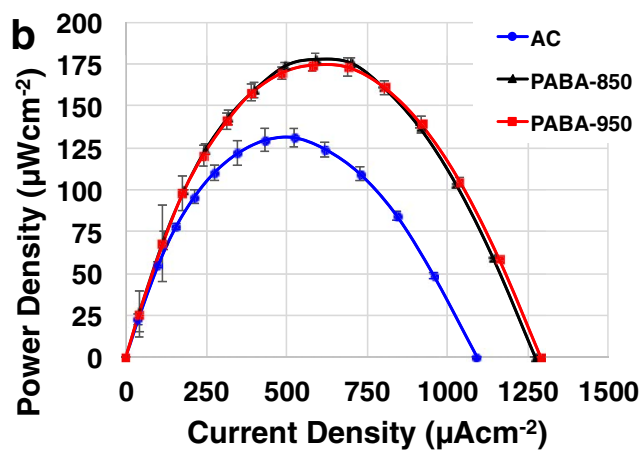

Figure 4. Polarization curves (a), power curves (b) and anode and cathode polarization curves of MFCs with AC, PABA-850 and PABA-950 catalysts. 
overcome to improve the overall MFC performance. For this reason, before performing the tests in MFC, kinetics analysis using RRDE technique was done on the plain catalyst. RRDE data showed similar performances for Fe-PABA-850 and Fe-PABA-950. AC performances were very poor compared to Fe-based catalyst. This trend was also confirmed when the catalyst was incorporated in an air-breathing cathode and tested in running MFC. Fe-based cathode outperformed ACcathode. Lately, several works in literature incorporated PGM-free based catalysts into an air-breathing cathode often based on activated carbon pellet. ${ }^{11,12,18}$ A reasonable comparison is not possible due to the different operating conditions that certainly affect the output performances. In fact, solution conductivity, cell design, and temperature affect the performances output. In this manuscript, a comparison with platinum was not done because platinum is very expensive and consequently not suitable for application in bioelectrochemical systems, and it was shown before that platinum work for less than 1 week before being poisoned and deactivated by anions naturally present into the sludge. ${ }^{45,52}$ The maximum performances achieved in this investigation were $178 \pm 3 \mu \mathrm{Wcm}^{-2}$ that is slightly lower compared with previously presented data with PGM-free catalyst. ${ }^{52}$ This might be due to the reduced catalysts loading that in this study was $1 \mathrm{mg} \mathrm{cm}^{-2}$, exactly half compared to previous works. Further investigation should be addressing the effect of the loading on the performances output. Neverthless, the value obtained is quite high for an MFC having a not optimized configuration (distance between anode and cathode of $7 \mathrm{~cm}$ ), a volume of $125 \mathrm{~mL}$ and room temperature operating conditions. $\mathrm{Fe},{ }^{31-35} \mathrm{Mn},{ }^{36,37} \mathrm{Cu}^{43} \mathrm{Ni}^{41,42}$ and $\mathrm{Co}^{38-40}$ have been recently presented as PGM-free catalysts. In similar electrolyte conductivity conditions to the one here investigated, PGM-free catalysts incorporated into $\mathrm{AC}$ cathodes had performances varying between 150 and $200 \mu \mathrm{Wcm}^{-2}$. It must be noticed that generally, Fe-based catalysts is the best performing among the PGM-free catalysts. Another important aspect to mention is related to the durability of the PGM-free cathodes facing directly the electrolyte containing pollutants. While the interaction of anions with $\mathrm{Pt}$ is well known, interestingly, previous works showed good performances in durability tests done on Fe-based cathodes working for 1 month $^{45,52}$ and 12 months $^{27}$ respectively.

At last, an important consideration regarding material cost has to be done. PGM-free catalysts are made with earth abundant metals ( $\mathrm{Fe}$, $\mathrm{Co}, \mathrm{Mn}, \mathrm{Ni}, \mathrm{Cu}$ ) and consequently are much more competitive and cheaper compared with costly PGM catalysts. The catalysts investigated demonstrated high power density, low cost production and they might used for real world applications.

\section{Conclusions}

Novel iron based catalysts synthesized using polymer salt pyrolysis technique were tested in RRDE and MFCs. Morphology of the novel catalysts showed a porous structure with graphitic flakes containing a large number of holes. Kinetics of Fe-based catalysts was superior compared to AC. The best electro-catalytic activity was achieved for PABA-850. The Fe-based catalyst was then integrated into air breathing cathodes and tested in the working MFCs. Fe-catalysts had the higher power density recorded that was $178 \pm 3 \mu \mathrm{Wcm}^{-2}$ by PABA- 850 and $173 \pm 3 \mu \mathrm{Wcm}^{-2}$ by PABA-950. At last, $\mathrm{AC}$ had a power peak of $131 \pm 4 \mu \mathrm{Wcm}^{-2}$. The advantage in performances of the utilization of Fe-based catalysts justifies the application of PGMfree catalysts in the air-breathing cathode. Fe-based catalysts are a novel and cheap alternative to a platinum group based catalysts in MFC.

\section{Acknowledgments}

The authors thank the Bill \& Melinda Gates Foundation grant: "Efficient Microbial Bio-electrochemical Systems" (OPP1139954).

\section{References}

1. S. Calabrese Barton, J. Gallaway, and P. Atanassov, Chem. Soc. Rev., 104, 4867 (2004)
2. P. Pandey, V. N. Shinde, R. L. Deopurkar, S. P. Kale, S. A. Patil, and D. Pant, Appl. Energy, 168, 706 (2016)

3. F. Zhao, R. C. T. Slade, and J. R. Varcoe, Chem. Soc. Rev., 38, 1926 (2009).

4. A. E. Franks and K. P. Nevin, Energies, 3, 899 (2010).

5. Hamid Rismani-Yazdi, Sarah M. Carver, Ann D. Christy, and Olli H. Tuovinen, J. Power Sources, 180, 683 (2008).

6. B. Erable, D. Feron, and A. Bergel, ChemSusChem, 5, 975, (2012).

7. C. Santoro, S. Babanova, P. Atanassov, B. Li, I. Ieropoulos, and P. Cristiani, J. Electrochem. Soc., 160, H720 (2013).

8. R. D. Milton and S. D. Minteer, J. Electrochem. Soc., 161, H3011 (2014).

9. A. Shrier, F. Giroud, M. Rasmussen, and S. D. Minteer, J. Electrochem. Soc., 161, H244 (2014).

10. C. Santoro, S. Babanova, B. Erable, A. Schuler, and P. Atanassov. Bioelectrochem., 108, 1 (2016).

11. Z. Wang, C. Cao, Y. Zheng, S. Chen, and F. Zhao, ChemElectroChem, 1, 1813 (2014).

12. E. Antolini, Biosens. Bioelectron., 69, 54 (2015).

13. Marcus D. Pohl, Viktor Colic, Daniel Scieszka, and Aliaksandr S. Bandarenka, Phys.Chem.Chem.Phys., 18, 10792 (2016).

14. C. Santoro, A. Serov, C. W. Narvaez Villarrubia, S. Stariha, S. Babanova, A. J. Schuler, K. Artyushkova, and P. Atanassov, ChemSusChem, 8, 828 (2015).

15. Kh. M. Minachev, N. I. Shuikin, and I. D. Rozhdestivenskaya, B. Acad. Sci. USSR $\mathrm{CH}+, \mathbf{1}, 567$ (1952).

16. G.A Somorjai, J. Catal., 27, 453 (1972).

17. K. Guo, A. Prévoteau, S. A. Patil, and K. Rabaey, Curr. Opin. Biotechnol., 33, 149 (2015).

18. H. Yuan, Y. Hou, I. M. Abu Reesh, J. Chen, and Z. He. Mater. Horiz., 3, 382 (2016).

19. C. Santoro, K. Artyushkova, S. Babanova, P. Atanassov, I. Ieropoulos, M. Grattieri, P. Cristiani, S. Trasatti, B. Li, and A. J. Schuler. Bioresour. Technol., 163, 54 (2014).

20. I. Gajda, J. Greenman, C. Melhuish, and I. Ieropoulos, Bioelectrochem., 104, 58 (2015).

21. I. Gajda, J. Greenman, C. Melhuish, and I. Ieropoulos, Sci. Rep., 6, 25571 (2016).

22. V. J. Watson, C. N. Delgado, and B. E. Logan, Environ. Sci. Technol., 47, 6704 (2013).

23. B. Wei, J. C. Tokash, G. Chen, M. A. Hickner, and B. E. Logan, RSC Adv., 2, 12751 (2012).

24. F. Zhang, S. Cheng, D. Pant, G. Van Bogaert, and B. E. Logan. Electrochem. Commun., 11, 2177 (2009).

25. H. Dong, H. Yu, H. Yu, N. Gao, and X. Wang, J. Power Sources, 232, 132 (2013).

26. X. Zhang, X. Xia, I. Ivanov, X. Huang, and B. E. Logan, Environ. Sci. Technol., 48, 2075 (2014).

27. X. Zhang, D. Pant, F. Zhang, J. Liu, and B. E. Logan, ChemElectroChem, 1, 1859 (2014).

28. S. Diodati, E. Negro, K. Vezzù, V. Di Noto, and S. Gross, Electrochim. Acta, 215 , 398 (2016)

29. C. H. Choi, C. Baldizzone, J.-P. Grote, A. K. Schuppert, F. Jaouen, and K. J. J. Mayrhofer, Angew. Chem. Int. Ed. Engl., 54, 12753 (2015)

30. C. H. Choi, C. Baldizzone, G. Polymeros, E. Pizzutilo, O. Kasian, A. K. Schuppert, N. R. Sahraie, M.-T. Sougrati, K. J. J. Mayrhofer, and F. Jaouen, ACS Catal., 6, 3136 (2016).

31. X. Xia, F. Zhang, X. Zhang, P. Liang, X. Huang, and Bruce E. Logan, ACS Appl. Mater. Interfaces, 5, 7862 (2013).

32. G. Lu, Y. Zhu, L. Lu, K. Xu, H. Wang, Y. Jin, Z. J. Ren, Z. Liu, and W. Zhang, J. Power Sources, 315, 302 (2016).

33. L. Birry, P. Mehta, F. Jaouen, J. P. Dodelet, S. R. Guiot, and B. Tartakovsky, Electrochim. Acta, 56, 1505 (2011).

34. M.-T. Nguyen, B. Mecheri, A. D'Epifanio, T. P. Sciarria, F. Adani, and S. Licoccia, Int. J. Hydrogen Energy, 39, 6462 (2014).

35. M.-T. Nguyen, B. Mecheri, A. Iannaci, A. D'Epifanio, and S. Licoccia, Electrochim Acta, 190, 388 (2016).

36. E. Martin, B. Tartakovsky, and O. Savadogo, Electrochim. Acta, 58, 58 (2011).

37. X. Li, B. Hu, S. Suib, Y. Lei, and B. Li, J. Power Sources, 195, 2586 (2010).

38. B. Liu, C. Brückner, Y. Lei, Y. Cheng, C. Santoro, and B. Li, J. Power Sources, 257, 246 (2014).

39. B. Ge, K. Li, Z. Fu, L. Pu, and X. Zhang, Bioresour. Technol., 195, 180 (2015).

40. F. Zhao, F. Harnisch, U. Schröder, F. Scholz, P. Bogdanoff, and I. Herrmann, Electrochem. Commun., 7, 1405 (2005).

41. L. Z. Zeng, S. F. Zhao, and W. S. Li, Appl Biochem Biotechnol., 175, 2637 (2015).

42. J. Huang, N. Zhu, T. Yang, T. Zhang, P. Wu, and Z. Dang, Biosens. Bioelectron., 72, $332(2015)$.

43. X. Zhang, K. Li, P. Yan, Z. Liu, and L. Pu, Bioresour. Technol., 187, 299 (2015)

44. C. Santoro, K. Artyushkova, I. Gajda, S. Babanova, A. Serov, P. Atanassov, J. Greenman, I. Ieropoulos, A. Colombo, S. Trasatti, and P. Cristiani, Int. J. Hydrogen Energy, 40, 14706 (2015).

45. C. Santoro, A. Serov, C. W. Narvaez Villarrubia, S. Stariha, S. Babanova, K. Artyushkova, A. J. Schuler, and P. Atanassov, Sci. Rep., 5, 16596 (2015).

46. J. Houghton, C. Santoro, F. Soavi, A. Serov, I. Ieropoulos, C. Arbizzani, and P. Atanassov, Bioresour. Technol., 218, 552 (2016).

47. C. Santoro, F. Soavi, A. Serov, C. Arbizzani, and P. Atanassov, Biosens. Bioelectron., 78, 229 (2016).

48. A. Serov, M. Padilla, A. J. Roy, P. Atanassov, T. Sakamoto, K. Asazawa, and H. Tanaka, Angew. Chem. Int. Ed. Engl., 126, 10504 (2014)

49. A. Serov, K. Artyushkova, E. Niangar, C. Wang, N. Dale, F. Jaouen, M.-T. Sougrati, Q. Jia, S. Mukerjee, and P. Atanassov, Nano Energy, 16, 293 (2015).

50. A. Serov, K. Artyushkova, N. I. Andersen, S. Stariha, and P. Atanassov, Electrochim. Acta, 179, 154 (2015) 
51. C. Santoro, A. Serov, S. Rojas-Carbonell, L. Stariha, J. Gordon, K. Artyushkova, and P. Atanassov Novel Fe-N-C Catalysts from Organic Precursors for Neutral Media and Microbial Fuel Cell Application. Abstract \# 1825. 229th ECS meeting San Diego, CA.
52. C. Santoro, A. Serov, L. Stariha, M. Kodali, J. Gordon, S. Babanova, O. Bretschger, K. Artyushkova, and P. Atanassov, Energy Environ. Sci., 9, 2346 (2016).

53. R. Gokhale, V. Aravindan, P. Yadav, S. Jain, D. Phase, S. Madhavi, and S. Ogale, Carbon, 80, 462 (2014). 